\title{
CARACTERIZAÇÃO MORFOLÓGICA E GERMINAÇÃO DE SEMENTES DE JALAPA (Operculina macrocarpa (L.)Urb.) ${ }^{1}$
}

\author{
BEATRIZ GONÇALVES BRASILEIRO², MARIA CARMEN BHERING ${ }^{3}$, \\ DEBORAH DE SOUZA VIDIGAL ${ }^{2}$, VICENTE WAGNER DIAS CASALI ${ }^{4}$
}

\begin{abstract}
RESUMO - O objetivo deste trabalho foi avaliar a presença da dormência tegumentar, identificando tratamentos pré-germinativos que possam acelerar e uniformizar a germinação, bem como conhecer a morfologia do desenvolvimento pós seminal em sementes de Operculina macrocarpa. As sementes foram submetidas aos seguintes tratamentos pré-germinativos: imersão em água por 1 hora; imersão em solução de hipoclorito por 1 hora e testemunha, representada por sementes sem tratamento prévio. Os testes de germinação e de emergência foram conduzidos com quatro repetições de 25 e de 20 sementes, em laboratório e em casa-de-vegetação, respectivamente. As avaliações foram realizadas diariamente, durante 30 dias, onde foi calculada a porcentagem de plântulas normais aos 15 e 30 dias e o índice de velocidade de germinação/emergência. A germinação de Operculina macrocarpa é epígea-fanerocotiledonar e a semente apesar de apresentar um tegumento duro não se mostra impermeável à entrada de água, dispensando a adoção de tratamentos pré-germinativos.
\end{abstract}

Termos para indexação: Dormência, Operculina macrocarpa (L.) Urb., tegumento, planta medicinal.

\section{MORFOLOGICAL CHARACTERIZATION AND GERMINATION OF JALAPA (Operculina macrocarpa $(\mathrm{L}.) \mathrm{Urb}$.) SEEDS}

\begin{abstract}
The objective of this study was to evaluate the presence of tegumentar dormancy and identify pre-germination treatments that can unify and accelerate the germination and know the morphology of the seminal development in post-seed of Operculina macrocarpa. The seeds were subjected to the following pre-germination treatments: immersion in water for 1 hour; immersion in hypochlorite solution for 1 hour and the control, represented by seeds without pretreatment. Germination and emergence tests were conducted with four replications of 25 and 20 seeds, carried out in the laboratory and greenhouse, respectively. Evaluations were conducted daily, for 30 days and the percentage of normal seedlings (15 and 30 days) and the rate of speed germination/emergency were calculated. The germination of Operculina macrocarpa is epigeous-phanerocotylar and the seed, although it has a hard seed coat, was not shown to be impermeable to water and thus does not require pre-germination treatments.
\end{abstract}

Index terms: Dormancy, Operculina macrocarpa (L.) Urb., teguments, medicinal plant.

${ }^{1}$ Submetido em 08/07/2008. Aceito para publicação em 30/03/2009.

${ }^{2}$ Doutoranda do Programa de Pós-Graduação, Departamento de Fitotecnia da UFV- Viçosa - MG; emails: beatrizgb@vicosa.ufv.br, e-mail: dsvidigal@gmail.com
${ }^{3}$ Pesquisadora, MS, Departamento de Fitotecnia da UFV- Viçosa - MG; email: mbhering@ufv.br

${ }^{4}$ Professor Titular do Departamento de Fitotecnia da Universidade Federal de Viçosa - UFV, 36571-000 - Viçosa - MG; email: vwcasali@ufv.br 


\section{INTRODUÇ̃̃O}

A importância medicinal, econômica e ecológica de espécies nativas brasileiras, bem como o risco de sua extinção pela ação predatória do homem, tem motivado estudos destas plantas, visando sua preservação e aproveitamento racional. Entretanto, somente uma pequena parte das espécies medicinais tem sido apropriadamente estudada. Um problema associado com a disponibilidade das plantas medicinais é a falta de um eficiente e prático método de produção, para o que, estudos da germinação e dormência das sementes são fundamentais na exploração sustentável destas espécies.

Operculina macrocarpa (L.) Urb. (Convolvulaceae) é uma espécie bianual, com grande potencial farmacológico e muito comum no Nordeste do Brasil, cujo nome popular é batata-de-purga ou jalapa. É uma trepadeira de aspecto ornamental que possui folhas palmatiformes, flores brancas e frutos contendo, em sua maioria, 4 sementes negras e duras. Suas raízes tuberosas, grandes, amiláceas e lactescentes são motivo de grande comércio para fins medicinais (Lorenzi e Matos, 2002). Os principais componentes das raízes são a fécula e a resina (12\%), a qual é formada pela mistura complexa de substâncias de natureza glicosídica polimérica, de propriedade purgativa, sendo reconhecida como laxante ou, em doses maiores, como purgativo drástico e antielmíntico (Mors et al., 2000, Michelin e Salgado, 2004).

As raízes tuberosas desta planta são fontes tradicionais de remédios da medicina popular do nordeste, cujas primeiras referências sobre seu uso remontam a mais de dois séculos (Matos, 1991). A literatura etnobotânica registra o emprego de suas raízes em preparações diversas no tratamento de asma juvenil e de casos de paralisias parciais resultantes de AVC (Acidente Vascular Cerebral) (Lorenzi e Matos, 2002). Entretanto, todas as preparações caseiras ou industriais da batata-de-purga devem ser usadas com cuidado, pois em doses mais altas que as aconselhadas podem causar intoxicação severa, traduzida por cólicas fortes e diarréia intensa, com risco de rápida desidratação (Matos, 2002).

As sementes de $O$. macrocarpa apresentam obstáculos para a germinação, pelo fato de serem cobertas por um tegumento duro, que impede a penetração de água e gases (Medeiros Filho et al., 2002). A impermeabilidade do tegumento à água é desenvolvida durante a maturação da semente (Baskin e Baskin, 1998) e ocorre em 16 Famílias de Angiospermas sendo, 1 família pertencente às monocotiledôneas e 15 famílias às dicotiledôneas, incluindo nesta a família Convolvulaceae (Baskin e Baskin, 2000; Baskin et al., 2006). A formação de sementes duras contribui para a distribuição temporal da germinação, situação desejável em termos de preservação da espécie, que reduz os riscos da emergência simultânea de uma população de sementes. Entretanto, este fato é considerado prejudicial à agricultura onde se deseja que as sementes germinem num curto espaço de tempo, produzindo mudas uniformes (Marcos Filho, 2005).

Os métodos empregados na superação da dormência causada pela impermeabilidade do tegumento deverão promover o enfraquecimento ou a ruptura do tegumento, permitindo a embebição e posterior germinação, como ocorre com a escarificação química ou mecânica (Zaidan e Barbedo, 2004). Entretanto, parte dos métodos disponíveis tem emprego restrito em condições de laboratório ou apresenta certo grau de periculosidade, como é o caso da escarificação química. Isto reforça a necessidade de outros estudos enfocando métodos práticos e alternativos visando à superação da dormência de sementes, principalmente em espécies medicinais. Trabalhos realizados por Meireles (2004) mostraram que a pré-embebição das sementes de cafeeiro em solução aquosa de hipoclorito de sódio, contendo 5,0\% de cloro ativo, durante um período de 6 horas, foi eficiente na degradação do pergaminho sem causar danos ao embrião, proporcionando percentagem e velocidade de germinação semelhante à remoção manual do pergaminho.

Apesar da sua grande utilização pela população, existem poucos estudos agronômicos sobre a Operculina macrocarpa, principalmente relacionado à germinação de sementes. Considerando a dureza do tegumento e a dificuldade de escarificação, o objetivo deste trabalho foi avaliar a presença da dormência, identificando tratamentos pré-germinativos que possam acelerar e uniformizar a germinação, bem como conhecer a morfologia do desenvolvimento pós-seminal em sementes de $O$. macrocarpa.

\section{MATERIAL E MÉTODOS}

O trabalho foi desenvolvido no Laboratório de Análise de Sementes e em Casa de Vegetação do Departamento de Fitotecnia da Universidade Federal de Viçosa, em Viçosa MG. Foram utilizadas sementes de Operculina macrocarpa (L.) Urb. colhidas, de uma mesma planta, em maio de 2006 e em maio de 2007. As sementes colhidas em maio de 2006 foram armazenadas por um ano antes da utilização. As sementes permaneceram armazenadas em sacos de papel, em ambiente natural de laboratório, sem controle da temperatura e da umidade do ar, até o início dos testes. Para a caracterização física das sementes, foi realizado, antes das 
avaliações fisiológicas, o peso de mil sementes, o número de sementes por quilograma e o grau de umidade, segundo as recomendações das Regras para Análise de Sementes (Brasil, 1992). O grau de umidade foi determinado pelo método da estufa a $105 \pm 3^{\circ} \mathrm{C}$ durante 24 horas, utilizando-se três repetições.

Curva de embebição: A curva de embebição foi determinada por meio da pesagem inicial de quatro repetições de 25 sementes de cada ano. A seguir, as sementes foram colocadas para embeber em água destilada em condições de laboratório, sendo pesadas após, 3, 6, 9, 12, 24, 36, 48, 60 e 72h de embebição, em balança com precisão de $0,001 \mathrm{~g}$. Antes de cada pesagem, as sementes foram secadas com papel absorvente para retiradas de água superficial e posteriormente recolocadas em água destilada, para continuação da embebição. Com os valores das pesagens consecutivas foi calculada a percentagem média de ganho de água em relação ao peso inicial das sementes, para a plotagem da curva de embebição.

Germinação das sementes: Após os tratamentos prégerminativos, foram distribuídas quatro repetições de 25 sementes sobre duas folhas de papel germitest previamente umedecidas com quantidade de água 2,5 vezes o peso do papel seco. Posteriormente foram confeccionados os rolos e levados ao germinador a $25^{\circ} \mathrm{C}$. A primeira contagem de germinação foi realizada aos 15 dias e a contagem final se deu aos 30 dias com a completa estabilização do estande. A porcentagem de germinação foi, então, calculada computando-se o total de plântulas normais germinadas aos 30 dias após a semeadura. Avaliou-se também a porcentagem de sementes duras e mortas e o índice de velocidade de germinação, o qual foi realizado simultaneamente ao teste de germinação, sendo anotado diariamente o número de sementes germinadas, tendo como critério a emissão da raiz primária com comprimento igual ou superior a $1,0 \mathrm{~cm}$. $\mathrm{O}$ índice de velocidade de germinação foi calculado segundo Maguire (1962).

Emergência em casa-de-vegetação: Para a semeadura foram utilizados sacos perfurados de polietileno preto $(10 \times 20 \mathrm{~cm})$ contendo substrato preparado com solo e esterco na proporção 3:1. Foi utilizado o delineamento inteiramente casualizado com 4 repetições, sendo que cada unidade experimental foi constituída por 20 saquinhos, dispostos em 1 fileira. A semeadura foi feita colocando-se uma semente em cada saquinho, a uma profundidade de $3 \mathrm{~cm}$, que foi irrigado diariamente, sempre no período da manhã. As seguintes avaliações foram realizadas: Índice de velocidade de emergência (IVE) - a partir da emergência da primeira plântula foram realizadas contagens diárias do numero de plântulas emergidas até que o valor permanecesse constante, sendo consideradas emergidas as plântulas que apresentavam cotilédones acima do substrato e o calculo realizado segundo Maguire (1962); Emergência - a última contagem do IVE foi considerada para o cálculo da percentagem de emergência das plântulas; Primeira contagem da emergência - foi obtida a porcentagem de plântulas normais no décimo quinto dia após a instalação do teste.

Caracterização das plântulas e da germinação: A caracterização da germinação e a descrição morfológica do desenvolvimento pós-seminal foram realizadas durante o teste de germinação das sementes em laboratório, utilizandose rolo de papel e 4 repetições de 25 sementes de cada ano. As ilustrações foram feitas manualmente, em tamanho real, com o auxílio de uma câmara clara e microscópio estereoscópico binocular. As descrições foram feitas de acordo com as características morfológicas das estruturas em cada estádio de desenvolvimento, por meio de observações diárias e utilizando-se as plântulas e mudas mais vigorosas. Os processos de desenvolvimento e de diferenciação dos estádios foram descritos caracterizando-se todas as etapas do processo de germinação, ou seja, protusão da radícula, desenvolvimento do eixo hipocótilo-radícula, emissão dos cotilédones e emissão da plúmula.

Procedimento estatístico: Os dados obtidos foram submetidos à análise de variância, comparando-se as médias pelo teste Tukey, a 5\% de probabilidade.

\section{RESULTADOS E DISCUSSÃO}

As características físicas das sementes encontram-se na Tabela 1 onde se observa que as sementes colhidas em 2006 apresentaram maior tamanho, o que pode ser atribuído às condições ambientais ou mesmo a algum tipo de sazonalidade. As sementes maduras de Operculina macrocarpa (Figura 2A), são subglobosas, com lado dorsal fortemente convexo e com um sulco inconspícuo no centro; hilo suborbicular, com 3,0-3,5mm de comprimento, afundado, emarginado na base, fosco, glabo, circundado por um estreito sulco, da mesma coloração; superfície do tegumento lisa e glaba, preta e fosca. O tecido de reserva envolve os cotilédones e varia de transparente a esbranquiçado, de carnoso a gelatinoso quando a semente está hidratada (Figura 2B), e córneo quando não hidratada. Como não foi feito o estudo de ontogenia das sementes, segue-se a sugestão de Aqüila (2004) e denominase o tecido de reserva como albúmen. O embrião é axial, com dois cotilédones foliáceos, bem desenvolvidos, adnatos, 
opostos e iguais, de coloração amarelada, com bordo ondulado que se invagina na base, no ponto de inserção do eixo hipocótilo-radícula, que é reto, curto, de coloração amarelo-esbranquiçada, com plúmula rudimentar (Figura 2C).

TABELA1 . Características físicas da semente de Operculina macrocarpa (L.) Urb. Laboratório de Análise de Sementes.

\begin{tabular}{lrr}
\hline \multirow{2}{*}{ Características } & \multicolumn{2}{c}{ Ano de colheita } \\
\cline { 2 - 3 } & 2006 & 2007 \\
\hline Umidade (\%) & 13,63 & 14,69 \\
Peso de mil sementes $(\mathrm{g})$ & 576,03 & 335,95 \\
Número de sementes/kg & 1740 & 2978 \\
\hline
\end{tabular}

Germinação de $\boldsymbol{O}$. macrocarpa: Com relação às determinações fisiológicas realizadas no laboratório, verificase na Tabela 2, que a germinação das sementes colhidas em 2007 foi estatisticamente superior às das sementes colhidas em 2006, para todos os tratamentos pré-germinativos utilizados. Esta superioridade das sementes colhidas em 2007, em relação às colhidas em 2006 e armazenadas por um ano, foi também observada no teste de emergência realizado na casa-de-vegetação, pelos testes de primeira contagem de emergência, emergência e índice de velocidade de emergência (Tabela 3). Ainda na Tabela 2, verifica-se que os resultados dos testes de primeira contagem, germinação e índice de velocidade de germinação, para as sementes colhidas em 2006, não diferiram significativamente, entre os tratamentos pré-germinativos utilizados. No entanto, para as sementes colhidas em 2007, aquelas que permaneceram imersas em água durante 1 hora apresentaram germinação significativamente inferior aos outros dois tratamentos, ou seja, imersão em hipoclorito e sementes sem tratamento pré-germinativo, o mesmo ocorrendo com o índice de velocidade de germinação. Os resultados obtidos, utilizando solo como substrato, em casa-de-vegetação (Tabela 3), seguiram a mesma tendência daqueles obtidos em condições de laboratório. Resultados satisfatórios, usando imersão em hipoclorito, também foram obtidos com sementes de café (Meireles, 2004; Sofiatti et al., 2008) e sementes de Commiphora lepthophloes (Faiad et al., 1997).

TABELA 2. Primeira contagem de germinação (PCG), germinação(G) e índice de velocidade de germinação (IVG) de sementes de Operculina macrocarpa (L.) Urb. submetidas aos tratamentos pré-germinativos. Laboratório de Análise de Sementes.

\begin{tabular}{|c|c|c|c|c|c|c|}
\hline \multirow{2}{*}{ TRATAMENTOS } & \multicolumn{2}{|c|}{ PCG $(\%)$} & \multicolumn{2}{|c|}{$\mathrm{G}(\%)$} & \multicolumn{2}{|c|}{ IVG } \\
\hline & 2006 & 2007 & 2006 & 2007 & 2006 & 2007 \\
\hline Testemunha & $24 \mathrm{Ab}$ & 92Aa & $49 \mathrm{Ab}$ & 93Aa & $1,49 \mathrm{Ab}$ & $4,05 \mathrm{Aa}$ \\
\hline Imersão em água, por $1 \mathrm{~h}$ & $29 \mathrm{Ab}$ & $75 \mathrm{Ba}$ & $47 \mathrm{Ab}$ & $77 \mathrm{Ba}$ & $1,49 \mathrm{Ab}$ & $3,42 \mathrm{Ba}$ \\
\hline Imersão em hipoclorito, por $1 \mathrm{~h}$ & $28 \mathrm{Ab}$ & 94Aa & $40 \mathrm{Ab}$ & 94Aa & $1,64 \mathrm{Ab}$ & $5,08 \mathrm{Aa}$ \\
\hline C.V. $(\%)$ & 12,47 & 10,90 & 16,92 & 8,48 & 12,96 & 10,84 \\
\hline
\end{tabular}

Médias seguidas da mesma letra, maiúscula na coluna e minúscula na linha, não diferem entre si, pelo teste de Tukey a 5\% de probabilidade.

Estes resultados mostraram que as sementes de Operculina macrocarpa não apresentaram dormência, mas sofreram um decréscimo na viabilidade após o período de um ano de armazenamento. Um dos sintomas mais evidentes do declínio do potencial fisiológico das sementes é a redução da velocidade de germinação (Marcos Filho, 2005).

A ausência da dormência tegumentar também pode ser verificada pelos resultados obtidos na curva de embebição da semente de Operculina macrocarpa (Figura 1), indicando que o tegumento não impossibilitou a entrada de água na semente. A absorção de água foi mais rápida nas primeiras 24 horas quando a massa de matéria fresca das sementes atingiu $63,64 \%$ em relação a massa inicial. A partir deste período a embebição ocorreu em menor quantidade. A curva de embebição se constitui num importante procedimento técnico para auxiliar na identificação do tipo específico de dormência apresentado pela semente, sobretudo associado à dureza e impermeabilidade do tegumento (Almeida, 2001). Estes resultados diferem daqueles obtidos por Medeiros Filho et al. (2002) que concluíram que Operculina 
macrocarpa apresenta sementes dormentes devido a dureza do tegumento, destacando a escarificação mecânica como o método mais eficiente para a superação desta dormência. Esta divergência pode estar associada às diferenças ambientais e as diferenças genéticas das populações estudadas, uma vez que a impermeabilidade do tegumento a água é uma característica genética altamente influenciada pelo ambiente (Marcos Filho, 2005).

TABELA 3. Primeira contagem de emergência (PCE), emergência (E) e índice de velocidade de emergência (IVE) em casa-de-vegetação, de sementes de Operculina macrocarpa (L.) Urb. submetidas aos tratamentos prégerminativos. Laboratório de Análise de Sementes.

\begin{tabular}{|c|c|c|c|c|c|c|}
\hline \multirow{2}{*}{ TRATAMENTOS } & \multicolumn{2}{|c|}{ PCE $(\%)$} & \multicolumn{2}{|c|}{$\mathrm{E}(\%)$} & \multicolumn{2}{|c|}{ IVE } \\
\hline & 2006 & 2007 & 2006 & 2007 & 2006 & 2007 \\
\hline Testemunha & $16 \mathrm{Ab}$ & $25 \mathrm{Ba}$ & $23 \mathrm{Ab}$ & $76 \mathrm{Aa}$ & $0,29 \mathrm{Ab}$ & $0,90 \mathrm{Aa}$ \\
\hline Imersão em água, por $1 \mathrm{~h}$ & $13 \mathrm{Ab}$ & $29 \mathrm{Ba}$ & $23 \mathrm{Ab}$ & $67 \mathrm{Ba}$ & $0,29 \mathrm{Ab}$ & $0,82 \mathrm{Ba}$ \\
\hline Imersão em hipoclorito, por $1 \mathrm{~h}$ & $15 \mathrm{Ab}$ & $42 \mathrm{Aa}$ & $29 \mathrm{Ab}$ & 78Aa & $0,34 \mathrm{Ab}$ & $0,98 \mathrm{Aa}$ \\
\hline C.V. $(\%)$ & 45,74 & 28,72 & 28,64 & 4,88 & 31,36 & 5,96 \\
\hline
\end{tabular}

Médias seguidas da mesma letra, maiúscula na coluna e minúscula na linha, não diferem entre si, pelo teste de Tukey a 5\% de probabilidade.

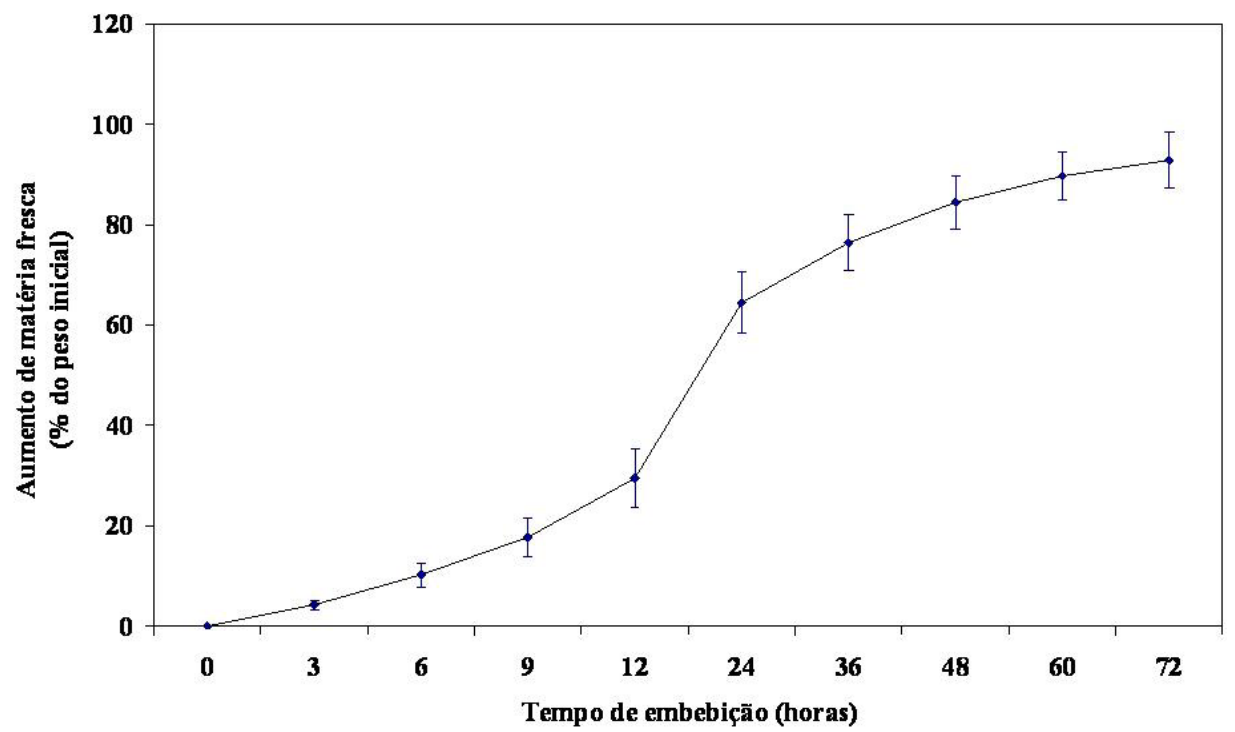

FIGURA 1. Curva de embebição em água das sementes de Operculina macrocarpa (L.) Urb. Laboratório de Pesquisa em Sementes.

Aspectos morfológicos da germinação: Do ponto de vista morfológico, a germinação iniciou-se no $5^{\circ}$ dia, caracterizado pela protrusão da radícula, a qual rompeu o tegumento na região próxima ao hilo (Figura
2D). A raiz primária alonga-se rapidamente, sendo cilíndrica, espessa, glabra e tenra (Figura 3A-C). A partir do $6^{\circ}$ dia os cotilédones iniciam o rompimento do tegumento, até a completa remoção, quando emergem 
e se expandem entre o $10^{\circ}$ e o $12^{\circ}$ dia (Figura 3D-E), passando da coloração amarela para verde. Neste período ( $6^{\circ}$ dia), também tem início o aparecimento das primeiras raízes secundárias. A plântula normal apresenta folhas cotiledonares persistentes e raiz principal robusta e muitas raízes secundárias (Figura $3 \mathrm{~F})$. O curto epicótilo eleva a plúmula por volta do $15^{\circ}$ dia. Protófilos simples surgem quando os cotilédones estão semi-abertos, projetando-se para fora, entre os pecíolos cotiledonares (Figura 3G). A região do coleto é caracterizada por um distinto anelamento de coloração levemente rósea e por apresentar um leve afinamento em relação ao diâmetro da raiz. No $18^{\circ}$ dia, fica caracterizada a plântula normal, fanerocotiledonar, originada de germinação epígea. Segundo as Regras para Análise de Sementes (Brasil, 1992) uma planta normal deve ter todas as suas estruturas essenciais presente, desenvolvidas e saudáveis como pode ser observado na Figura 3G. Quando este padrão não ocorre, as plântulas são classificadas como anormais.
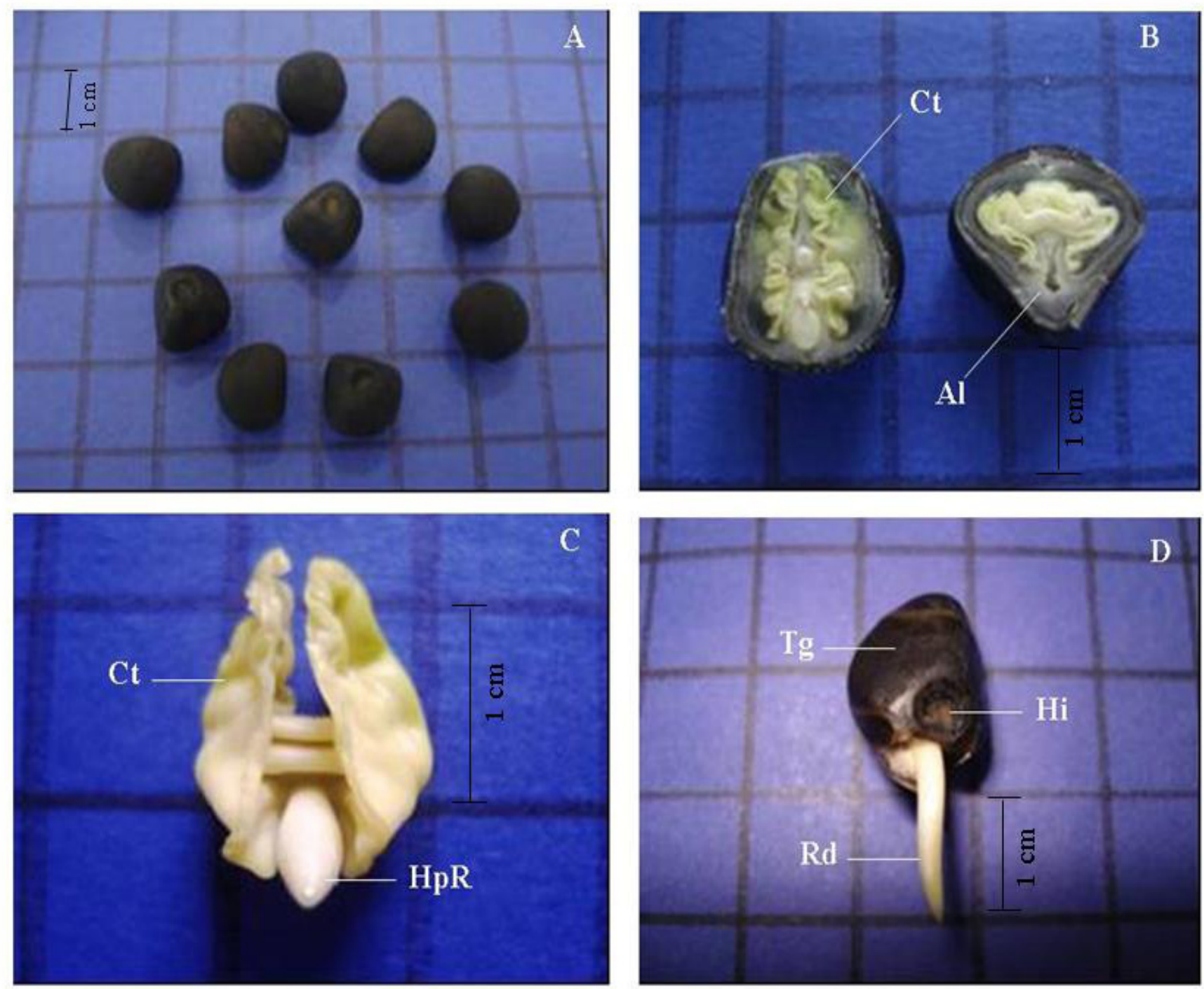

FIGURA 2. Aspectos morfológicos da semente e da germinação de jalapa (O. macrocarpa (L.) Urb.): A- vista externa; B- vista interna (após 24 horas de embebição); C- embrião (após 24 horas de embebição); D- protusão da radícula. Legenda: $\mathrm{Ct}=$ cotilédone; $\mathrm{Hi}=$ hilo; $\mathrm{Tg}=$ tegumento; $\mathrm{Rd}=$ radícula; $\mathrm{Al}=$ albumem; $\mathrm{HpR}=$ Eixo hipocótilo-radícula. Laboratório de Pesquisa em Sementes. 


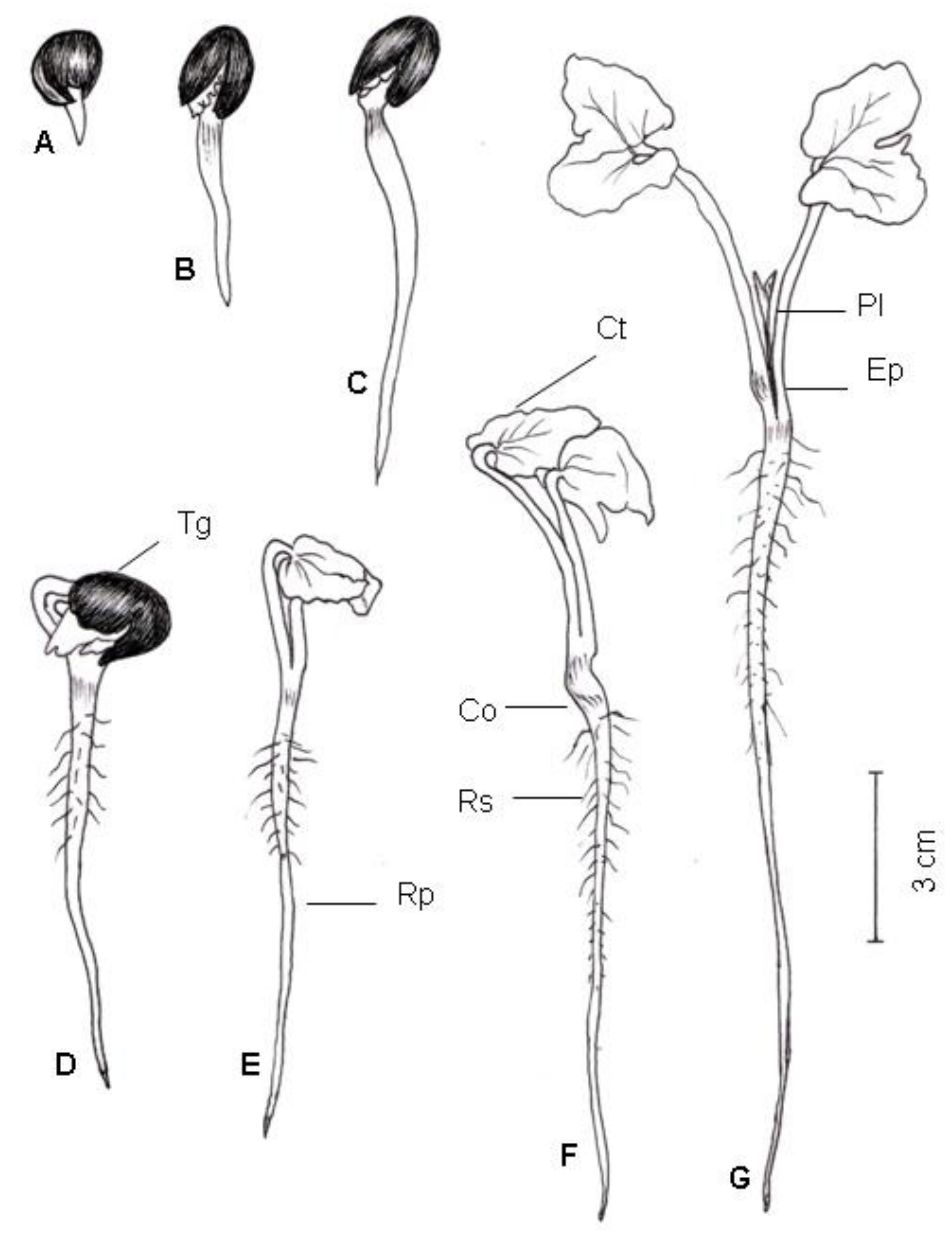

FIGURA 3. Aspectos morfológicos do processo germinativo de jalapa (O. macrocarpa (L.) Urb.). Legenda: Ct $=$ cotilédone; $\mathrm{Co}=$ coleto; $\mathrm{Ep}=$ epicótilo; $\mathrm{Tg}=$ tegumento; $\mathrm{Rd}=$ radícula; $\mathrm{Rp}=$ raiz primária; $\mathrm{Rs}=\mathrm{raiz}$ secundária; $\mathrm{Pl}=$ plúmula. Laboratório de Pesquisa em Sementes.

O monitoramento do processo da germinação possibilitou a caracterização dos estádios do desenvolvimento pósseminal, desde a protrusão da radícula, ocorrida no quinto dia após a semeadura até a emissão da plúmula. Assim, pode-se propor uma contagem intermediária aos 15 dias, onde as plântulas encontram-se no estádio intermediário do desenvolvimento e, uma contagem final, aos 30 dias após a semeadura, quando do estabelecimento da maioria das plântulas normais.

Aspectos morfológicos das mudas: Aos 15 dias após a germinação (20 dias após a semeadura), a muda (Figura 4) apresenta raiz primária longa, fina, cilíndrica, de coloração amarelada a ferrugínea-escura. Pouco ramificada, as raízes secundárias são finas, curtas, sinuosas, cilíndricas, tenras e da mesma coloração da raiz primária. Colo apresentando-se semelhante ao descrito na fase de plântula. Caule jovem com hipocótilo muito curto, glabro, marrom-avermelhado. Folhas cotiledonares persistentes, de limbo reniforme, liso e glabo, bilobados na base e na porção frontal, longo-peciolados, de nervação palminérvea, bem evidentes no caule, expondo duas gemas vegetativas pequenas e salientes nas axilas do pecíolo cotiledonar. Epicótilo com o primeiro internó marron-claro e acima dos protófilos longo, fino, reto e verde-claro. Protófilos de primeira ordem simples, alternos, longo-pecioladas, com limbo palmatipartido, com cinco segmentos de formato lanceolado, sendo o central mais comprido, de coloração verde e consistência membranácea, configurando o padrão da espécie. Presença de gemas axilares e caule volúvel. 


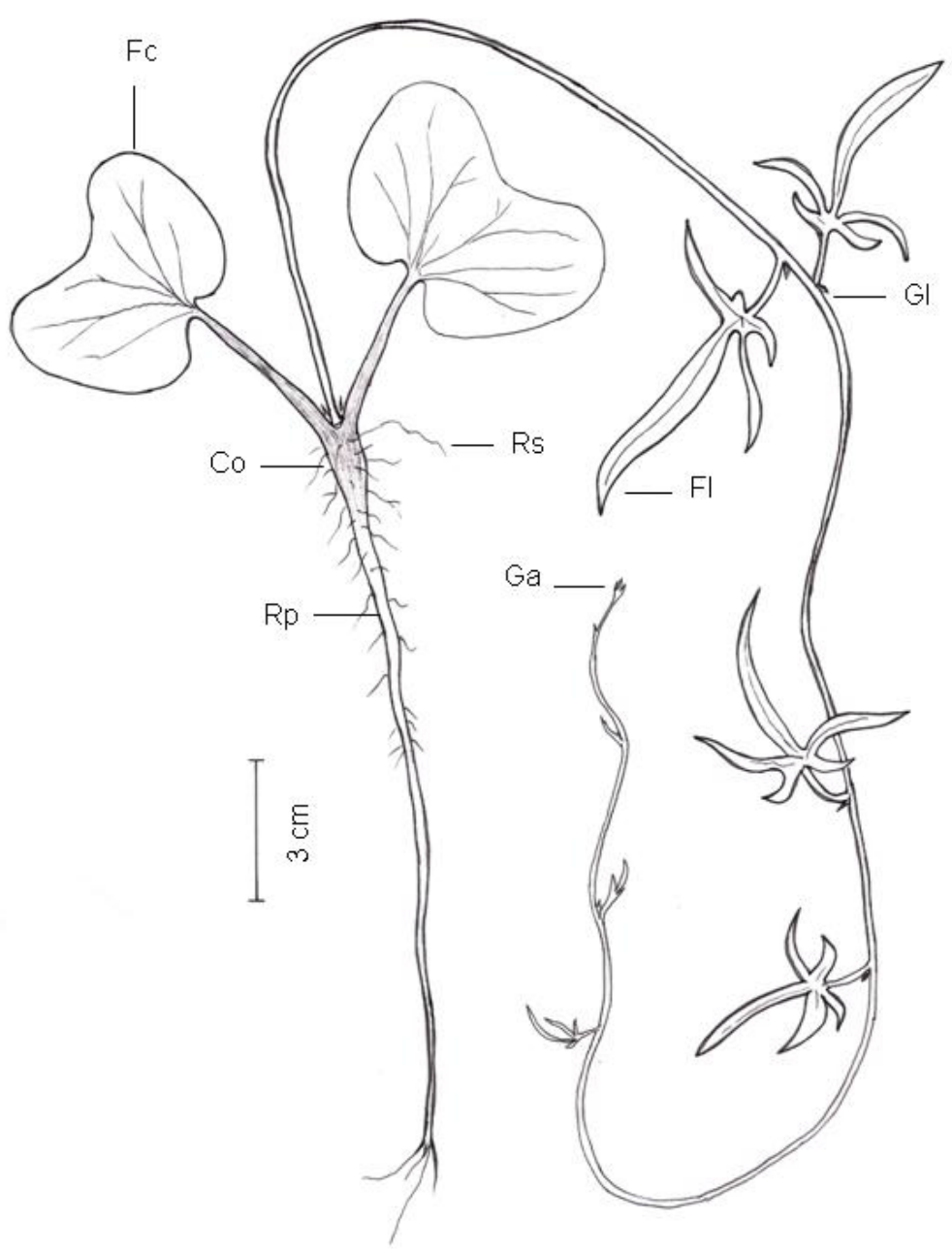

FIGURA4. Aspectos morfológicos de uma muda de jalapa (O. macrocarpa (L.) Urb.), com vinte dias de desenvolvimento. Legenda: $\mathrm{Fl}=$ folha; $\mathrm{Fc}=$ folha cotiledonar; $\mathrm{Co}=$ coleto; $\mathrm{Rp}=$ raiz primária; $\mathrm{Rs}=$ raiz secundária; $\mathbf{G a}=$ gema apical; Gl= gema lateral. Laboratório de Pesquisa em Sementes.

\section{CONCLUSÃO}

A germinação das sementes de Operculina macrocarpa é epígea e as plântulas são fanerocotiledonares;

Apesar de apresentarem um tegumento duro, as sementes de jalapa não se mostraram impermeáveis à entrada de água, dispensando a adoção de tratamentos pré-germinativos, nas condições deste ensaio.

\section{REFERÊNCIAS}

ALMEIDA, L.P. Germinação, crescimento inicial e anatomia foliar de plantas jovens de Cryptocarya aschersoniana Mez. sob diferentes níveis de radiação.
2001. 96 f. Dissertação (Mestrado em Agronomia. Fisiologia Vegetal) - Universidade Federal de Lavras, Lavras.

AQÜILA, M.E.A. Tipos de diásporos e suas origens. In: FERREIRA, A.G.; BORGHETTI, F. (Org.). Germinação: do básico ao aplicado. Porto Alegre: ARTMED, p.69-92, 2004.

BASKIN, J.M.; BASKIN, C.C. Evolutionary consideration of claims of physical dormancy-break by microbial action and abrasion by soil particles. Seed Science Research, v.10, n.4, p.409-413, 2000.

BASKIN,C.C.;BASKIN,J.M.Seeds-ecology,biogeography and evolution of dormancy and germination. New York: Academic Press, 1998. p.5-26. 
BASKIN, J.M.; BASKIN, C.C.; DIXON, K.W. Physical dormancy in the endemic Australian genus Stylobasium, a first report for the family Surianaceae (Fabales). Seed Science Research, v.16, n.3, p.229-232, 2006.

BRASIL. Ministério da Agricultura e Reforma Agrária. Secretaria Nacional de Defesa Agropecuária. Departamento Nacional de Produção Vegetal. Coordenação de Laboratório Vegetal. Regras para Análise de Sementes. Brasília, DF, 1992. $365 \mathrm{p}$.

FAIAD, M.G.R.; SALOMÃO, A.N.; CUNHA, R.; PADILHA, L.S. Efeito do hipoclorito de sódio sobre a qualidade fisiológica e sanitária de sementes de Commiphora lepthophloeos (Mart.) J. B. Gillet. Revista Brasileira de Sementes, v.19, n.1, p.14-17, 1997.

LORENZI, H.; MATOS, F.J.A. Plantas Medicinais no Brasil: nativas e exóticas. Nova Odessa: Instituto Plantarum, 2002. 512p.

MAGUIRE, J.D. Speed of germination-aid in selection and evaluation for seedling emergence and vigor. Crop Science, v.2, n.2, p.176-177, 1962.

MARCOS FILHO, J. Fisiologia de sementes de plantas cultivadas. FEALQ, Piracicaba, 2005. 495p.

MATOS, F.J.A. Plantas Medicinais-guia de seleção e emprego de plantas usadas em fitoterapia no nordeste do Brasil. Imprensa Universitária: UFC, Fortaleza, 2002. $344 p$.
MEDEIROS FILHO, S.; FRANÇA, E.A.; INNECCO, R. Germinação de sementes de Operculina macrocarpa (L.) Farwel e Operculina alata (Ham.)Urban. Revista Brasileira de Sementes, v.24, n.2, p.102-107, 2002.

MEIRELES, R.C. Efeito do hipoclorito de sódio e da embebição em água na germinação das sementes de café (Coffea arabica L.). 2004. 56 f. Dissertação (Mestrado em Fitotecnia). Departamento de Fitotecnia, Universidade Federal de Viçosa, Viçosa.

MICHELIN, D.C.; SALGADO, H.R.N. Avaliação da atividade laxante de Operculina macrocarpa L. Urban. Revista Brasileira de Farmacognosia, v.14, n.2, p.105109, 2004.

MORS, W.B.; RIZZINI, C.T.; PEREIRA, N.A. Medicinal Plants of Brasil. Reference Publications, Inc. Algonac, Michigan, 2000. 501p.

SOFIATTI, V.; ARAUJO, E.F.; ARAUJO, R.F.; REIS, M.S.; SILVA, L.V.B. D.; CARGNIN, A. Uso do hipoclorito de sódio para degradação do endocarpo de sementes de cafeeiro com diferentes graus de umidade. Revista Brasileira de Sementes, v.30, n.1, p.1-11, 2008.

ZAIDAN, L.B.P.; BARBEDO, C.J. Quebra de dormência em sementes. In: FERREIRA, A. G.; BORGHETTI, F. (Org.). Germinação: do básico ao aplicado. Porto Alegre: ARTMED, p.135-146, 2004. 